\begin{tabular}{c|c|c}
\hline & MARINE ECOLOGY PROGRESS SERIES \\
Vol. 240: 225-233, 2002 & Mar Ecol Prog Ser & Published September 12 \\
\hline \hline
\end{tabular}

\title{
Risk of collapse in the eastern Baltic cod fishery
}

\author{
Niclas Jonzén ${ }^{1,2, *}$, Massimiliano Cardinale ${ }^{3}$, Anna Gårdmark ${ }^{2}$, Fredrik Arrhenius ${ }^{3}$, \\ Per Lundberg ${ }^{2}$
}

\author{
${ }^{1}$ Department of Biology and Environmental Sciences, University of Jyväskylä, PO Box 35, 40351, Jyväskylä, Finland \\ ${ }^{2}$ Department of Theoretical Ecology, Ecology Building, Lund University, 22362 Lund, Sweden \\ ${ }^{3}$ National Board of Fisheries, Institute of Marine Research, PO Box 4, 45321 Lysekil, Sweden
}

\begin{abstract}
The eastern Baltic cod fishery, as many fisheries worldwide, is experiencing a major crisis. The combination of current environmental conditions, fishing mortality rates, and stock size indicates that this fishery is not sustainable. In order to rebuild the population and sustain the fishery in the future, it is essential to define a biologically appropriate exploitation level. In this paper, we take a decision-theoretical approach and use risk analysis to compare different management actions in terms of fishing mortality rates, and predict stock size in a short, medium and long-term perspective. We consider alternative hypotheses about the stock biomass in 1999 and analyse the risk of stock decline below three thresholds: quasi-extinction ( $B_{\text {ext }}$, defined by us), the safe biological limit, and the precautionary approach limit as defined by the International Council for the Exploration of the Sea (ICES). Results show that the current fishing mortality implies a tremendous risk of driving the Baltic cod stock below $B_{\text {ext }}(1000 \mathrm{t}$ ) within $10 \mathrm{yr}$. This result is robust to alternative assumptions about model structure as well as to the magnitude of environmental stochasticity. Hence, we consider a substantial reduction of the fishing mortality to be the only way of avoiding the far-reaching ecological and socio-economic consequences of continued exploitation at current levels.
\end{abstract}

KEY WORDS: Risk analysis · Stochastic population dynamics · Time series analysis · Gadus morhua · Baltic Sea

Resale or republication not permitted without written consent of the publisher

\section{INTRODUCTION}

Worldwide overfishing has raised concerns that extraordinary reductions in abundance may significantly increase the probability of (commercial) extinction of both exploited and incidentally harvested fish populations (Hutchings 2000). The spectacular collapse of enormous fish stocks such as North Sea herring Clupea harengus (Saville \& Baily 1980) — recently recovered-and Northern cod Gadus morhua off Newfoundland and Labrador (Hutchings \& Myers 1994, Myers et al. 1997) has puzzled scientists and frustrated marine resources managers. The North Sea

\footnotetext{
${ }^{*}$ Correspondence address: Department of Theoretical Ecology, Ecology Building, Lund University, 22362 Lund, Sweden. E-mail: niclas.jonzen@teorekol.lu.se
}

cod fishery is considered to be on the verge of collapse (Cook et al. 1997) and recently (February 2001) the fishery has been partially closed due to the lowest level of cod abundance ever reached in the last century (ICES 2001a).

Yet another cod stock - the eastern Baltic cod-is currently getting much attention due to documented recruitment failures and the consequent decrease in stock size in recent years (Vallin et al. 1999, Cardinale \& Arrhenius 2000, Hjerne \& Hansson 2001, Köster et al. 2001). From the mid 1980s, the eastern stock (ICES subdivisions 25 to 32 ) has declined dramatically and recruitment has been at low levels since 1989 (ICES 1999, Kuikka et al. 1999). Cod is the dominant piscivore in the Baltic Sea and one of its the most valuable commercial species (Bagge et al. 1994). Since 1974, ICES has been giving advice to IBSFC (The International Baltic Sea Fishery Commission) and its contract- 
ing parties in the major Baltic cod fisheries (ICES 1999). The stock is managed by a TAC (total allowable catch) policy, where the TAC is set annually for the entire Baltic comprising both the western and the eastern stock (ICES 1999). However, the Baltic cod fishery is experiencing a major crisis (Cardinale \& Arrhenius 2000, Hjerne \& Hansson 2001). The combination of current environmental conditions, fishing mortality rates and stock size suggests that the Baltic cod fishery is not sustainable (Kuikka et al. 1999).

Much effort has been put into understanding recruitment dynamics (e.g. Köster et al. 2001). It has been widely accepted that favorable abiotic conditions are a crucial prerequisite for strong recruitment of Baltic cod (e.g. Sparholt 1996, Jarre-Teichmann et al. 2000, MacKenzie et al. 2000, Vallin \& Nissling 2000). Successful spawning of the Baltic cod, defined as successful development from egg to hatching, is restricted to the Bornholm, Gdansk and Gotland basin below the halocline, occurring at 50 to $80 \mathrm{~m}$ depth (Nissling \& Westin 1991). Egg buoyancy is affected by low salinity levels (Thorsen et al. 1996) and it is regarded as a major limiting factor for successful spawning of Baltic cod, since maintenance of low specific gravity is crucial in avoiding stressful oxygen conditions in deep water layers (Nissling \& Vallin 1996).

In order to rebuild the Baltic cod stock and sustain the fishery in the future, it is essential to define an exploitation level appropriate to these management objectives. From a management perspective, it is crucial to analyse the response of the stock to different management actions in face of uncertainty. Risk analysis offers this possibility (Cordue \& Francis 1994, Kuikka et al. 1999, Schnute et al. 2000) and is a suitable tool to define an appropriate exploitation level. Most risk analyses have focussed on parameter uncertainty (e.g. Walters \& Ludwig 1994), whereas structural uncertainty (model choice) may be more important (e.g. Punt \& Hilborn 1997, Kuikka et al. 1999, Patterson 1999). The framework of risk analysis should not be confused with the estimation of extinction risk per se. The true extinction risk can never be known and all estimates are doomed to be very uncertain due to the small amount of data (Dennis et al. 1991), neglect of catastrophes not observed in available data (Ludwig 1996, 1998), model uncertainty (Burnham \& Anderson 1998) and uncertainty about the relative importance of observation and process error in explaining the deviations between the fitted model and the data (Hilborn \& Walters 1992, Hilborn \& Mangel 1997, Quinn \& Deriso 1999). Estimates of extinction risks may therefore be more reliable for short-term than for long-term projections (Fieberg \& Ellner 2000).

In this paper, we were not interested in estimating risk per se, but rather in determining fishing mortality rates that prevent the stock biomass from falling below the suggested thresholds. We present a risk assessment based on the analyses of commercial catch data as well as catch rate data from experimental trawl survey for cod that is independent of the commercial fisheries. Such data have recently been used for estimating historical trend, exploitation rate and surplus production (Hilborn 2001). We are aware of the fact that modern fishery stock assessment often relies on a number of different data sources and often uses agestructured models. However, we are interested in the model predictions yielded by analysing univariate trawl survey data and using models that are adjusted to the information content in the data. By focussing on survey data we avoid all problems related to the reliability of VPA (Walters \& Maguire 1996) and reveal the information contained in a data source used in Baltic cod stock assessment, even though neglecting the age structure is likely to produce overoptimistic results because small fish only contribute to recruitment during extraordinarily good environmental conditions (Cardinale \& Arrhenius 2000).

The decision-theoretical approach taken here differs somewhat from that of stock assessments and projections performed annually by ICES. We used 2 alternative biomass models and introduced stochasticity either as process or observation error. For different hypotheses about stock size in 1999, we compared different management actions in terms of fishing mortality rates, and predicted stock size in a short, medium and long-term perspective. We analysed the probability of stock reduction below 3 thresholds: quasiextinction (defined by us), the safe biological limit, and the precautionary approach limit as defined by ICES (ICES 1999). Our approach and its result are compared to previous work by ICES (see 'Discussion').

\section{MATERIALS AND METHODS}

Data collection. We analysed fishery dependent data (commercial catch in $10^{3} \mathrm{t}$ ) and independent data (trawl survey) published in the ICES annual stock assessment reports (ICES 1999). The survey data (in $\mathrm{t} \mathrm{h}^{-1}$ ) were collected during the cod experimental trawl survey for cod by the Swedish RV 'Argos' (see Fig. 1 for the area covered by the survey). Sampling took place during daylight hours in February-March and October-November from 1980 to 1999 using a GOV (Grande Ouverture Vertical) trawl (Cardinale 2000) of $20 \mathrm{~mm}$ stretched mesh size in the cod-end. Standard fishing speed was 4 knots and each haul lasted 30 min (actual sampling time). Depth of sampling ranged from 30 to $125 \mathrm{~m}$. The analysis was based on catch and sampling data from ICES subdivisions 25 to 32 . 


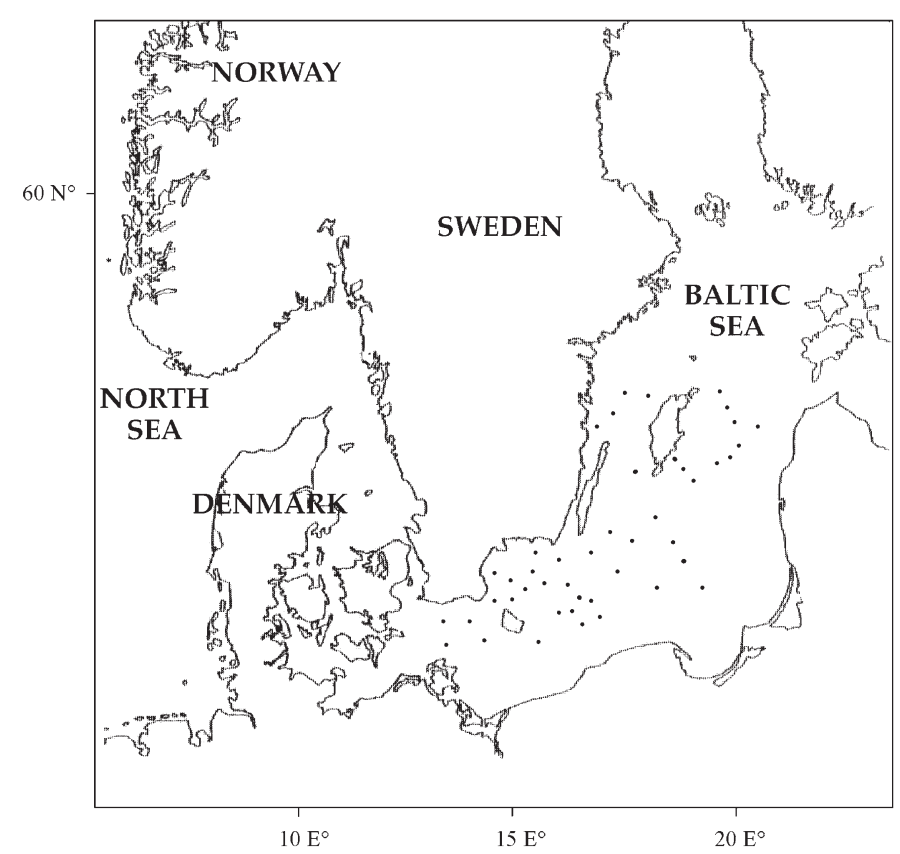

Fig. 1. The spatial location of the samples (black circles) collected during experimental trawl surveys for cod Gadus morhua with the Swedish RV 'Argos' in February-March and October-November, 1980 to 1999

Model. In a risk analysis, one or several models must be specified. One important feature is the model structure or complexity (Hilborn \& Mangel 1997). Simple models with few parameters are often preferable (Walters \& Ludwig 1985), but the optimal complexity in risk analysis models is not yet clear (Hilborn \& Mangel 1997, Pascual et al. 1997). Offspring survival, fecundity and fish growth rates vary significantly from year to year in the Baltic cod, depending on both hydrographic conditions, spatial location and species interactions (Köster et al. 2001), and this may cause a biomass model to be incapable of describing the population dynamics in detail. On the other hand, inclusion and estimation of additional parameters will increase the uncertainty of each estimate. Therefore, we used a simple biomass model to reduce the uncertainty in the functional relationships:

$$
B_{t+1}=B_{t} \mathrm{e}^{\left(r-d_{1} B_{t}-d_{2} B_{t-1}\right)}-C_{t}
$$

where $B_{t}$ and $C_{t}$ are, respectively, the stock biomass and the commercial catch (in $10^{3} \mathrm{t}$ ) in year $t_{i} r$ is the maximum per capita growth rate; and $d_{1}$ and $d_{2}$ are the strength of direct and delayed density dependence, respectively.

Delayed density dependence can occur due to a number of processes (see Royama 1992) and has recently been demonstrated in Skagerrak populations of Atlantic cod (Bjørnstad et al. 1999, Stenseth et al.
1999, Fromentin et al. 2001). We use 2 versions of Eq. (1), including $\left(d_{2} \neq 0\right)$ or excluding $\left(d_{2}=0\right)$ delayed density dependence. However, the estimate of $d_{2}$ was approximately equal to zero and Akaike's information criterion corrected for small sample size (Burnham \& Anderson 1998) was in favour of the model having only direct density dependence (AIC difference $=3.5$ ). Furthermore, our results were not affected by having the model include or exclude delayed density dependence, and we computed the results based on the latter.

The relationship between the survey index $I_{t}$ and the actual biomass is assumed to be linear such that:

$$
I_{t}=q B_{t}
$$

where $q$ is the catchability, to convert the survey index into stock biomass in $10^{3} \mathrm{t}$.

Stochasticity can enter models as process error and/ or observation error. Stochasticity is an inherent property of ecological systems (Lundberg et al. 2000) and no sampling procedure is free of error. Hence, both sources of uncertainty are probably present in our data sets. As we cannot deal with both process and observation error simultaneously without having an estimate of the ratio between them (Hilborn \& Walters 1992), we made the extreme assumptions of having only process and only observation error, and compared the outcomes. Both process and observation errors were assumed to be log-normally distributed and uncorrelated. Hence, the stochastic versions of the model, excluding delayed density dependence, are:

$$
\begin{gathered}
B_{t+1}=\left(B_{t} \mathrm{e}^{\left(r-d_{1} B_{t}\right)}-C_{t}\right) \mathrm{e}^{\left(u_{t} \sigma_{u}-0.5 \sigma_{u}^{2}\right)} \\
I_{t}=q B_{t} \mathrm{e}^{\left(w_{t} \sigma_{w}-0.5 \sigma_{w}^{2}\right)}
\end{gathered}
$$

where $\sigma_{u}$ and $\sigma_{w}$ are the standard deviation of process uncertainty and observation uncertainty, respectively (e.g. Hilborn \& Mangel 1997).

Risk analysis. A risk (or decision) analysis involves the following steps (Punt \& Hilborn 1997): (1) identification of alternative hypotheses, (2) determination of the relative weight of evidence in support of each hypothesis, (3) identification of alternative management actions, and (4) evaluation of the distribution and expected value of each performance measure for different management actions and hypotheses. Finally, the results are presented to decision-makers.

In most fisheries the estimated biomass is an uncertain entity, and we therefore considered five different hypotheses on cod biomass in 1999, ranging from 100000 to $300000 \mathrm{t}$ in steps of $50000 \mathrm{t}$. The probability of each hypothesis was given by the relative likelihood. More explicitly, a penalty function was added to the negative log-likelihood, forcing the estimated bio- 
mass in 1999 to be close to the target for each of the hypotheses. Hence, we minimised:

$$
F\left(r, q, d_{1}\right)=\sum_{t} L_{t}+C\left(B_{1999}^{\text {pred }}-B_{1999}^{\text {hypothesis }}\right)^{2}
$$

where $L_{t}$ is the negative log-likelihood for year $t$, and $c$ scales the magnitude of the penalty function, i.e. the squared deviation between the predicted and target biomass in 1999; for details see Hilborn \& Mangel (1997, p 254-255). We calculated the total likelihood for each hypothesis and divided it by the sum of likelihoods over all admitted hypotheses on stock biomass in 1999. This 'relative probability' is proportional to Bayes' posterior probability when choosing a uniform prior (Walters \& Ludwig 1994).

We assumed 11 different management actions in terms of fishing mortality ranging from 0 to 1 in steps of 0.1 . For each hypothesis of the biomass and for each management action we ran the model (using the corresponding parameter estimates) during 5 (short term), 10 (medium term) and 30 yr (long term). When running the Monte Carlo simulations, we assumed lognormal noise (as in the estimation procedure) and let the standard deviation of the noise be either 0.1 or 0.2 . The reason why we cannot use the estimated standard deviation of the error is that the estimation was built on the assumption of having only process (or observation) error. Hence, the estimates will contain the noise from both sources of uncertainty and exceed the true value.

For each combination of hypotheses and management actions, we ran 10000 iterations. We calculated the proportion of the iterations when the stock biomass ended up below $B_{\text {ext }}=1000 \mathrm{t}, B_{\lim }=160000 \mathrm{t}$ and $B_{\mathrm{pa}}=$ $240000 \mathrm{t}$ at the end of the specified time span. Strictly speaking, one cannot talk about commercial extinction without explicitly considering economic factors. However, we consider it rather unlikely that commercial exploitation would be allowed if the stock drops below $B_{\text {ext }}$. ICES defines $B_{\lim }$ as the biomass below which the stock is outside the safe biological limit (ICES 1999). The uppermost limit, $B_{\mathrm{pa}}$ (= the precautionary approach limit), is the biomass below which action should be taken (ICES 1999). Finally, according to the most recent assessment (ICES 2001b), the spawning stock biomass in 1999 may have been as low as $75000 \mathrm{t}$, far below previous assessment of 116000 tons (ICES 2000), and we repeated the risk calculations assuming that this was the true biomass in 1999.

\section{RESULTS}

It is unclear to what extent deviations between models and data derive from process error and observation error. The model assuming process error predicts stock dynamics that correspond to the observed stock fluctuations in the 1990s reasonably well, whereas the model assuming observation error gives predictions that average out these fluctuations (Fig. 2A). Furthermore, the relative probability of the hypotheses about stock biomass in 1999 depends on these assumptions. The uncertainty in spawning stock biomass (SSB, Fig. 2B) was caused by a very strong correlation between the estimates of $r$ and $q$, and the estimates of biomass are much higher than those of ICES. However, when considering alternative hypotheses about stock biomass in 1999 between 100000 and 300000 t, the expected marginal risk of ending up below a critical biomass limit after 5, 10 or $30 \mathrm{yr}$, is only marginally influenced by the assumptions about the source of uncertainty and about the standard deviation ( 0.1 or 0.2 ) of the noise (Fig. 3 ). Hence, despite the uncertainty about current cod biomass, the results are rather robust. Also, exploitation according to $F_{\mathrm{pa}}$ - the fishing mortality above which management actions should be taken, which is set at 0.6 - is very unlikely to let the stock recover; the biomass will therefore not exceed the precautionary approach limit or the safe biological limit at any time in the future. The average fishing mortality in the last 2 decades $(0.9)$ is indeed very likely to push the population below $B_{\text {ext }}$ within $10 \mathrm{yr}$.

In Table 1, we present full decision tables for the probability of a biomass lower than $B_{\lim }(160000 \mathrm{t})$ after 5 yr, assuming either process or observation error (the other decision tables can be requested from N.J.) Note that the risk of falling below $B_{\text {lim }}$ increases with increasing biomass in 1999, due to negative correlation between $r$ and the biomass in 1999 in the estimates of the relative probability of each hypothesis. If the biomass is low, the stock will be close to the threshold, but will also have a high $r$-value which can sustain a higher fishing mortality than a low $r$-value would. Hence, there will be a trade-off between stock size and population growth rate in the statistical estimation procedure (Fig. 2C). In Fig. 3, the expected marginal value (EMV) of each fishing mortality in terms of risk is plotted for different time spans (5, 10 and $30 \mathrm{yr})$, assumptions on stochasticity (process error or observation error), and reference points ( $B_{\text {ext }}, B_{\lim }$ and $\left.B_{\mathrm{pa}}\right)$. The calculation of EMV is explained in Table 1, and all the decision tables are summarised in Fig. 3. For instance, Table 1A has a column with expected marginal values below $B_{\text {lim }}$ after 5 yr when process error is assumed, and these values correspond to one of the curves (solid with *) in Fig. 3C.

Forcing the predicted biomass in 1999 to be $75000 \mathrm{t}$, as indicated by the most recent assessment (ICES 2001b), we obtained similar results to those based above on the assumption of observation error (Fig. 3D-F). Assuming process error instead, the model is not able 

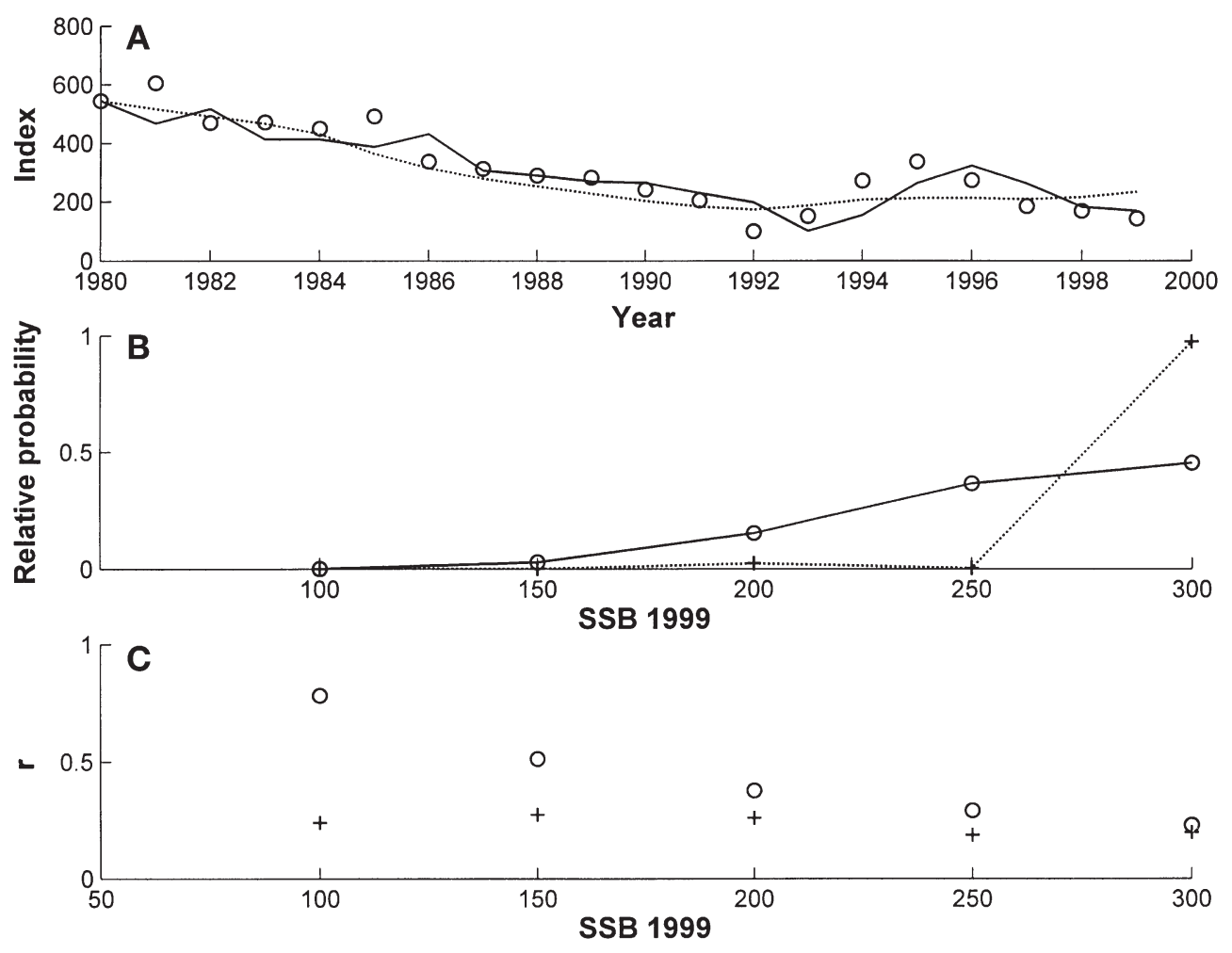

Fig. 2. Gadus morhua. (A) Abundance index (circles) from the Swedish trawl survey 1989-1999 and best fit of the model $B_{t+1}=B_{t} \mathrm{e}^{\left(r-d_{1} B_{t}\right)}-C_{t}$, assuming a linear relationship between survey index and biomass $\left(I_{t}=q B_{t}\right)$; where $C_{t}$ is the commercial catch at time $t, r$ is the intrinsic growth rate and $d_{1}$ is the strength of direct density dependence. Solid line: assuming process error; dotted line: assuming observation error (lognormal error distribution with standard deviation $\sigma$ ). (B) Relative probability of stock biomass in 1999, assuming either process (solid line and O) or observation error (dotted line and +). Maximum likelihood estimates assuming process (or observation) error are: $r=0.097(0.19), d_{1}=-3.5 \times 10^{-5}\left(-2.6 \times 10^{-11}\right), q=0.12(0.40)$, and $\sigma=0.28(0.24)$. (C) Estimate of $r_{1}$ assuming process (O) or observation (+) error for different hypotheses about biomass in 1999. SSB = spawning stock biomass

to capture the decreasing biomass trend indicated by the data, and the risk of ending up below any of the biomass thresholds is zero even for a fishing mortality $F=1$ (not shown).

\section{DISCUSSION}

Two major uncertainties in fishery managementincluding the eastern Baltic cod fishery-are the size or biomass of the exploited stock, and to what extent deviations between models and data are explained by stochasticity inherent to the system (process error) and uncertain observations (observation error). The latter is of course a far more general problem relevant to all quantitative sciences. We have dealt with both issues here and shown that much of the uncertainty about current stock size derives from the strong correlation between the catchability of the survey $(q)$ and maximum per capita growth rate $r$, a common problem in fisheries data analyses (Quinn \& Deriso 1999). The intrinsic growth rate is a key parameter in our model and the risk of quasi-extinction is inversely related to $r$. We have shown that the assumptions regarding process or observation error become increasingly important when current stock biomass is at the lower end of the biomass span 100000 to 300000 t (Fig. 2C), which appears to be the case according to the most recent stock assessment (ICES 2001b). Hence, the 2 sources of uncertainty (stock biomass and source of deviations between model and data) are intertwined. The risk evaluation accounts for this uncertainty by considering a range of different hypotheses on stock size in 1999yielding different estimates of the intrinsic growth rate ( $r$ ) - as well as by testing the 2 extreme assumptions of process error and observation error.

The average commercial fishing mortality has been 0.9 , i.e. higher than recommended by ICES, between the start of the Swedish experimental trawl survey in 1980 and the year 1998. According to our study, a fishing mortality of 0.9 implies a tremendous risk of driving the eastern Baltic cod stock below $B_{\text {ext }}(=1000 \mathrm{t})$ 

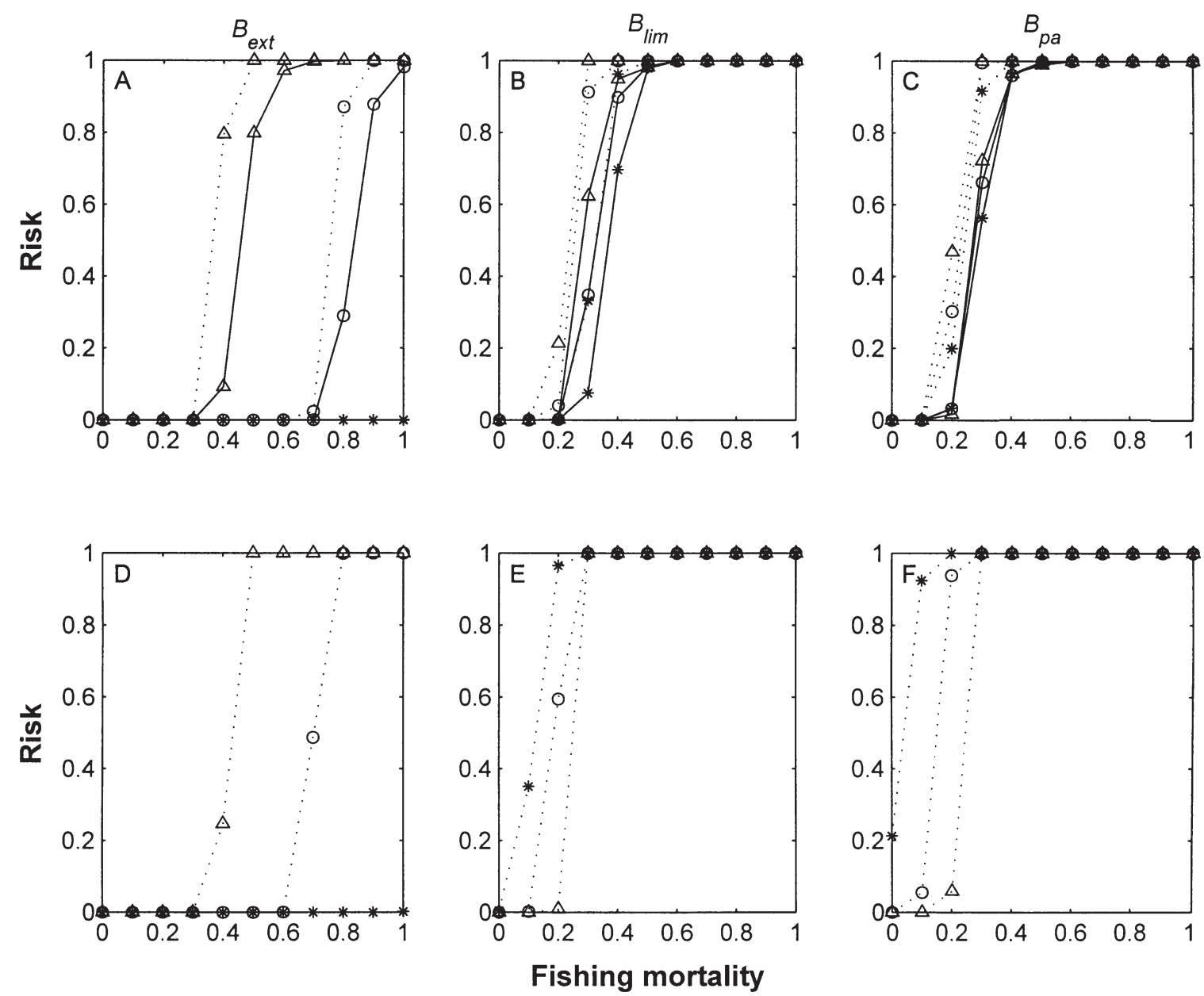

Fig. 3. Gadus morhua. Expected marginal risk of attaining stock sizes below $B_{\mathrm{ext}}=1000 \mathrm{t}, B_{\lim }=160000 \mathrm{t}$ and $B_{\mathrm{pa}}=240000 \mathrm{t}$ after $5 \mathrm{yr}$ (lines with $*$ ), $10 \mathrm{yr}$ (lines with $\mathbf{0}$ ) and $30 \mathrm{yr}$ (lines with $\Delta$ ), as a function of fishing mortality. Parameter estimates based on the assumption of log-normal process error (solid lines) or observation error (dotted lines). The standard deviation of the noise in Monte Carlo simulations was 0.1. Panels D-F: assumption of a biomass of $75000 \mathrm{t}$ in 1999, and observation error only

within 10 yr. This result is independent of the magnitude of the noise, the assumption on process or observation error, or whether the model includes delayed density dependence or not. In addition, the so-called $F_{\mathrm{pa}}$ - the fishing mortality above which management action should be taken, which is currently set at 0.6 (ICES 2001b) - will lead to a stock biomass below $B_{\text {ext }}$ within 30 yr. Hence, our results reinforce the conclusions reached by ICES and buttress its repeated advice to reduce fishing mortality considerably to rebuild the stock. In fact, the most recent advice from ICES was that no fishery for Baltic cod should be permitted during 2002 (ICES 2001b).

The approach taken in this paper is different from (but complementary to) the Virtual Population Analysis (VPA) and stock projections carried out annually by ICES. A description and comparison of VPA and catchage assessment is presented in Quinn \& Deriso (1999), and we will merely highlight some of the differences between our approach and that of ICES. ICES' main tool for assessing the state of the stock is VPA tuned by the XSA (extended survivors analysis) method (Darby \& Flatman 1994). ICES estimates fishing mortality and numbers at age in the stock by using international catch-at-age and weight-at-age data, an assumed value of natural mortality $(Z=0.2)$, and survey data (including the data analysed in this paper) to estimate terminal stock size (see Darby \& Flatman 1994). Hence, ICES uses age-structured models and relies on both commercial catch data and independent surveys, whereas we have used biomass models without age structure and estimated the parameters by fitting the models to survey and catch data. ICES therefore uses more information, and the age-structured VPA model permits comparisons between age-selective fishing strategies. On the other hand, we have made fewer assumptions and used a simple model structure, and this should enhance the robustness of our conclusions. 
Table 1. Gadus morhua. Decision table showing the probability of obtaining a stock biomass below $B_{\lim }(160000 \mathrm{t})$ after $5 \mathrm{yr}$ (starting in 1999) at different fishing mortalities in the face of uncertainty about actual biomass in 1999. Parameter values used are estimations assuming (A) process error or (B) observation error. The noise in the Monte Carlo simulations was log-normal with $\sigma=0.1$. EMV: expected marginal value of each fishing mortality $f$, calculated according to $\operatorname{EMV}(f)=\Sigma \mathrm{P}\left(B_{\mathrm{i}}\right) P(f)$, where $\mathrm{P}\left(B_{\mathrm{i}}\right)$ is the probability of a given biomass in 1999, and $\mathrm{P}(f)$ is the probability of obtaining a stock biomass below $B_{\text {lim }}$ after 5 yr given $B_{i}$ and $f$. Values in parentheses: probability of the corresponding hypothesis

\begin{tabular}{|c|c|c|c|c|c|c|}
\hline Fishing & \multicolumn{5}{|c|}{ Alternative hypotheses about biomass $1999\left(10^{3} \mathrm{t}\right)$} & \multirow[t]{2}{*}{ EMV } \\
\hline \multicolumn{6}{|c|}{ (A) Assumption of process error } & \\
\hline & $\begin{array}{c}100 \\
(0.00)\end{array}$ & $\begin{array}{c}150 \\
(0.03)\end{array}$ & $\begin{array}{c}200 \\
(0.15)\end{array}$ & $\begin{array}{c}250 \\
(0.37)\end{array}$ & $\begin{array}{c}300 \\
(0.45)\end{array}$ & 298 \\
\hline$\leq 0.2$ & 0.00 & 0.00 & 0.00 & 0.00 & 0.00 & 0.00 \\
\hline 0.3 & 0.00 & 0.00 & 0.00 & 0.05 & 0.13 & 0.08 \\
\hline 0.4 & 0.00 & 0.02 & 0.34 & 0.70 & 0.86 & 0.70 \\
\hline 0.5 & 0.00 & 0.53 & 0.96 & 1.00 & 1.00 & 0.98 \\
\hline 0.6 & 0.03 & 0.99 & 1.00 & 1.00 & 1.00 & 1.00 \\
\hline 0.7 & 0.63 & 1.00 & 1.00 & 1.00 & 1.00 & 1.00 \\
\hline 0.8 & 0.99 & 1.00 & 1.00 & 1.00 & 1.00 & 1.00 \\
\hline$\geq 0.9$ & 1.00 & 1.00 & 1.00 & 1.00 & 1.00 & 1.00 \\
\hline \multicolumn{7}{|c|}{ (B) Assumption of observation error } \\
\hline & $\begin{array}{c}100 \\
(0.00)\end{array}$ & $\begin{array}{c}150 \\
(0.00)\end{array}$ & $\begin{array}{c}200 \\
(0.02)\end{array}$ & $\begin{array}{c}250 \\
(0.00)\end{array}$ & $\begin{array}{c}300 \\
(0.97)\end{array}$ & 262 \\
\hline$\leq 0.2$ & 0.66 & 0.03 & 0.01 & 0.20 & 0.04 & 0.04 \\
\hline 0.3 & 1.00 & 0.89 & 0.80 & 0.99 & 0.92 & 0.91 \\
\hline$\geq 0.4$ & 1.00 & 1.00 & 1.00 & 1.00 & 1.00 & 1.00 \\
\hline
\end{tabular}

\& Arrhenius 2000). Hence, neglecting age structure, as was done in this study, could produce overoptimistic results and the real situation could be even more severe than indicated here. Moreover, the recent decline in the Baltic cod biomass has been accompanied by an increase in population variability (Jonzén et al. 2001). Small population size, poor recruitment, strong fishing pressure, truncated population structure, and high population variability are strong indicators of imminent commercial extinction (Jonzén et al. 2001). However, because we have estimated the intrinsic growth rate from data collected during a period of poor recruitment, one could also argue that our estimates of future biomass are too pessimistic if recruitment improves in the future. There is of course no guarantee that this will happen, considering the complex interactions between age structure and environmental conditions underlying recruitment.

In this paper we have focussed solely on fishing mortality. However, an important realization in the last years is that fisheries management can benefit from an increased understand-

An important discussion in the management of Baltic cod is selectivity and, hence, the mesh sizes in the fishery (Kuikka et al. 1999). This type of management cannot be analysed in our model due to the lack of age/size structure. However, young spawners do not contribute much to the actual recruitment unless environmental conditions are very beneficial for egg development (Cardinale \& Arrhenius 2000). Increasing the mesh size would not solve the problem of loosing large and experienced spawners. Hence, we agree with ICES that mesh regulations alone are unlikely to let the stock return to safe biological limits (ICES 2001b) and the focus should be on the overall fishing mortality.

Historical data from ICES have clearly shown that recruitment of the Baltic cod has been low since the end of the 1980s due to to severe environmental conditions, and a substantially modified population age-structure due to high and selective fishing mortality (Cardinale \& Arrhenius 2000). Size-at-maturity has also decreased since the end of the 1980's, probably due to a combination of low population biomass and stressful environmental conditions (Cardinale \& Modin 1999). It implies that younger and smaller fish are able to reproduce although their contribution to recruitment is often negligible due to the low buoyancy of the eggs (Cardinale ing of environmental impact on populations (Beamish \& Mahnken 1999). Nevertheless, we should be aware that fishing mortality is often, if not always, the main reason why fish stocks collapse (Hutchings \& Myers 1994), and recovery may be a surprisingly slow process (Hutchings 2000). Furthermore, fishing mortality is the only variable possible to control in the short run, and as such it must be adapted to fluctuating environmental conditions. Future studies should be directed towards the recovery process. A theoretical understanding of the empirical patterns presented by Hutchings (2000) may change our perception of risk at low densities.

Predictions of recovery rate will always be uncertain, especially at very low density, where assumptions about process and observation error are critical (see Fig. 2C). We think, however, that our study highlights three important points. First, the conclusions reached by ICES, which constitute the basis of the advice given to the IBSFC (The International Baltic Sea Fishery Commission) and its contracting parties in the major Baltic cod fisheries, can be achieved by an alternative approach that may be easier to grasp for people who are not familiar with the methods and terminology of modern fish stock assessment. Second, our approach is not affected by the age-reading problems that are currently causing uncer- 
tainty with regard to the stock assessment (ICES 2001b). In fact, by using a simple model structure supported by the information in data, we make sure that our estimates are robust. Third, a decision-theoretical framework, as adopted here and elsewhere (e.g. Kuikka et al. 1999), can handle uncertainty and bridge the gap between ecological research and scientific advice.

Spectacular stock collapses and recent commercial extinctions should provide politicians, policy-makers, industry and fisheries managers with core evidence that it no longer makes sense to attribute collapses of marine resources to vaguely understood environmental causes (Hutchings \& Myers 1994). If it is urgent to intertwine stock assessment to ecosystem processes (Cardinale \& Arrhenius 2000), it is even more important to immediately reduce fishing pressure (this paper). We have used a different approach compared to ICES, but we arrive at similar results, reinforcing the message: Current fishing mortality will most likely lead to a reduction of the eastern Baltic cod stock far below any historical levels. Though the route to extinction is poorly understood (Ripa \& Lundberg 2000), the Baltic cod has most likely started the journey.

Acknowledgements. This study was supported by grants from The Swedish Natural Science Research Council, the Swedish Research Council for Forestry and Agriculture, and the Center of Excellence in Evolutionary Ecology at the Department of Biological and Environmental Science, University of Jyväskylä. The work was initiated when N.J. was a visiting scholar with Ray Hilborn at the University of Washington, Seattle. N.J. is grateful to Ray Hilborn for teaching the methods of risk analysis, and to the Swedish Institute, the Royal Physiographical Society in Lund, and the Spatial Ecology Program at the Department of Ecology and Systematics, University of Helsinki, for financial support. We thank Sture Hansson, Sakari Kuikka, and four anonymous referees for comments that improved this paper.

\section{LITERATURE CITED}

Bagge O, Thurow F, Steffenses E, Bay J (1994) The Baltic cod. Dana 10:1-28

Beamish RJ, Mahnken C (1999) Taking the next step in fisheries management. In: Ecosystem approaches for fisheries management. AK-SG-99-01. University of Alaska Sea Grant, Fairbanks, AL, p 1-22

Bjørnstad ON, Fromentin JM, Stenseth NC, Gjøsaeter J (1999) Cycles and trends in cod populations. Proc Natl Acad Sci USA 96:5066-5071

Burnham KP, Anderson DR (1998) Model selection and inference. A practical information-theoretic approach. SpringerVerlag, New York

Cardinale M (2000) Ontogenetic diet shift of bulltrout Myxocephalus scorpius (L.) in the south-western Baltic Sea. J Appl Ichthyol 16:231-239

Cardinale M, Arrhenius F (2000) The influence of stock structure and environmental conditions on the recruitment process of Baltic cod estimated using a Generalized Additive Model (GAM). Can J Fish Aquat Sci 57:2402-2409
Cardinale M, Modin J (1999) Changes in size-at-maturity of Baltic cod (Gadus morhua) during a period of large variations in stock size and environmental conditions. Fish Res 41:285-295

Cook RM, Sinclair A, Stefansson G (1997) Potential collapse of North Sea cod stocks. Nature 385:521-522

Cordue PL, Francis RICC (1994) Accuracy and choice in risk estimation for fisheries assessment. Can J Fish Aquat Sci 51:817-829

Darby CD, Flatman S (1994) Virtual Population Analysis, Version 3.1 (Windows/DOS) User guide. Info Tech Ser, MAFF Direct Fish Res, Lowestoft

Dennis, B, Munholland PL, Scott JM (1991) Estimation of growth and extinction parameters for endangered species. Ecol Monogr 61:115-143

Fieberg, J, Ellner SP (2000) When is it meaningful to estimate an extinction probability? Ecology 81:2040-2047

Fromentin JM, Myers RA, Bjørnstad ON, Stenseth NC, Gjøsaeter J, Christie H (2001) Effects of density-dependent and stochastic processes on the regulation of cod populations. Ecology 82:567-579

Hilborn R (2001) Calculation of biomass trend, exploitation rate, and surplus production from survey and catch data. Can J Fish Aquat Sci 58:579-584

Hilborn R, Mangel M (1997) The ecological detective. Confronting models with data. Princeton University Press, Princeton, NJ

Hilborn R, Walters CJ (1992) Quantitative fisheries stock assessment: Choice, dynamics \& uncertainty. Chapman \& Hall, New York

Hjerne O, Hansson S (2001) Constant catch or constant harvest rate? The Baltic Sea cod (Gadus morhua L.) fishery as a modelling example. Fish Res 53:57-70

Hutchings J (2000) Collapse and recovery of marine fishes. Nature 406:882-885

Hutchings J, Myers RA (1994) What can be learned from the collapse of a renewable resources? Atlantic cod, Gadus morhua, of Newfoundland and Labrador. Can J Fish Aquat Sci 51:2126-2146

ICES (1999) Stocks in the Baltic. Extract of the report of the Advisory Committee on Fishery Management, no. 6. ICES, May 1999

ICES (2000) Report of the Baltic Fisheries Assessment Working Group. ICES CM 2000/ACFM:14

ICES (2001a) Report of the Working Group on the Assessment of Demersal Stocks in the North Sea and Skagerrak. ICES CM 2001/ACFM:07

ICES (2001b) Report of the Baltic Fisheries Assessment Working Group. ICES CM 2001/ACFM:18

Jarre-Teichmann A, Wieland $\mathrm{K}$, MacKenzie R, Hinrichsen HH, Plikshs M, Aro E (2000) Stock-recruitment relationship for cod (Gadus morhua) in the central Baltic Sea incorporating environmental variability. Arch Fish Mar Res 48:97-123

Jonzén N, Lundberg P, Cardinale M, Arrhenius F (2001) Variable fishing mortality and the possible commercial extinction of the eastern Baltic cod. Mar Ecol Prog Ser 210:291-296

Köster FW, Hinrichsen HH, St. John MA, Schnack D, MacKenzie BR, Tomkiewicz J, Plikshs M (2001) Developing Baltic cod recruitment models. II. Incorporation of environmental variability and species interaction. Can J Fish Aquat Sci 58:1534-1556

Kuikka S, Hildén M, Gislason H, Hansson S, Sparholt H, Varis O (1999) Modeling environmentally driven uncertainties in Baltic cod (Gadus morhua) management by Bayesian influence diagrams. Can J Fish Aquat Sci 56:629-641 
Ludwig D (1996) The distribution of population survival times. Am Nat 147:506-526

Ludwig D (1998) Is it meaningful to estimate a probability of extinction? Ecology 80:298-310

Lundberg P, Ranta E, Ripa J, Kaitala V (2000) Population variability in space and time. Trends Ecol Evol 15:460-464

MacKenzie BR, Hinrichsen HH, Plikshs M, Zezera AS (2000) Quantifying environmental heterogeneity: estimating the size of habitat for successful cod egg development in the Baltic Sea. Mar Ecol Prog Ser 193:143-156

Myers RA, Hutchings JA, Barrowman NJ (1997) Why do fish stocks collapse: the example of cod in Atlantic Canada. Ecol Appl 7:91-106

Nissling A, Vallin L (1996) The ability of Baltic cod eggs to maintain neutral buoyancy and the opportunity for survival in fluctuating conditions in the Baltic Sea. J Fish Biol 48:217-227

Nissling A, Westin L (1991) Egg buoyancy of Baltic cod (Gadus morhua) and its implications for cod stock fluctuations in the Baltic. Mar Biol 111:33-35

Pascual MA, Kareiva P, Hilborn R (1997) The influence of model structure on conclusions about the viability and harvesting of Serengeti wildebeest. Conserv Biol 4: 966-976

Patterson KR (1999) Evaluating uncertainty in harvest control law catches using Bayesian Markov chain Monte Carlo virtual population analysis with adaptive rejection sampling and including structural uncertainty. Can J Fish Aqua Sci 56:208-221

Punt AE, Hilborn R (1997) Fisheries stock assessment and decision analysis: the Bayesian approach. Rev Fish Biol Fish 7:35-63

Quinn TJ II, Deriso RB (1999) Quantitative fish dynamics. Oxford University Press, New York

Ripa J, Lundberg P (2000) The route to extinction in variable environments. Oikos 90:89-96

Editorial responsibility: Otto Kinne (Editor), Oldendorf/Luhe, Germany
Royama T (1992) Analytical population dynamics. Chapman $\&$ Hall, London

Saville A, Bailey RS (1980) The assessment and management of the herring stocks in the North Sea and to the west of Scotland. Rapp P-V Reun Cons Int Explor Mer 177: $112-142$

Schnute JT, Cass A, Richards LJ (2000) A Bayesian decision analysis to set escapement goals for Fraser River sockeye salmon (Oncorhynchus nerka). Can J Fish Aquat Sci 57: 962-979

Sparholt H (1996) Causal correlation between recruitment and spawning stock size of central Baltic cod? ICES J Mar Sci 53:771-779

Stenseth NC, Bjørnstad ON, Falck W, Fromentin JM, Gjøsaeter J, Gray JS (1999) Dynamics of coastal cod populations: intra- and intercohort density dependence and stochastic processes. Proc R Soc Lond B 266:1645-1654

Thorsen A, Kjesbu OS, Fyhn HJ, Solemdal P (1996) Physiological mechanisms of buoyancy in eggs from brackish water cod. J Fish Biol 48:457-477

Vallin, L, Nissling A (2000) Maternal effects on egg size and egg buoyancy of Baltic cod, Gadus morhua-implications for stock structure effects on recruitment. Fish Res 49: 21-37

Vallin L, Nissling A, Westin L (1999) Potential factors influencing reproductive success of Baltic cod, Gadus morhua: a review. Ambio 28:92-99

Walters CJ, Ludwig D (1985) Are age-structured models appropriate for catch-effort data? Can J Fish Aquat Sci 42: 1066-1072

Walters CJ, Ludwig D (1994) Calculation of Bayes posterior probability distribution for key population parameters. Can J Fish Aquat Sci 51:713-722

Walters CJ, Maguire JJ (1996) Lessons for stock assessment from the northern cod collapse. Rev Fish Biol Fish 6: 125-137

Submitted: December 4, 2001; Accepted: June 6, 2002 Proofs received from author(s): August 19, 2002 